\title{
Factors Predicting Explicit and Implicit Attitudes Towards Body Scanners
}

\author{
Magdalena Laib a,c, Larissa Wolkenstein b,c \\ anformation Experience and Design Research Group, Stuttgart Media University. \\ b Division of Clinical Psychology and Psychotherapy, Ludwig-Maximilians-University Munich. \\ c Division of Clinical Psychology and Psychotherapy, University of Tübingen.
}

${ }^{*}$ Corresponding author's email address: Magdalena.Laib@hdm-stuttgart.de

\section{A R T I C L E I N F O}

Received: 26-03-2016

Accepted: 21-04-2016

Available online: 26-05-2016

Keywords:

Body scanner;

explicit attitude;

implicit attitude;

Security technology;

ST-IAT.

JEL Classification:

C12 - Hypothesis Testing;

C90 - General (Design of experiments);

L93 - Air Transportation ;

033 - Technological Change:

Choices and Consequences

\section{A B S T R A C T}

Many ethical concerns have been raised about the implementation of body scanners at airports. However, no study thus far has investigated which factors influence the attitudes of the general public towards body scanners. Thus, the current study aimed to find variables predicting the implicit and explicit attitudes towards body scanners. Different sociodemographic and personality variables have been taken into account. Explicit attitudes were assessed by a questionnaire and implicit attitudes were assessed by the Single Target Implicit Association Test. Women worried more about the effects of a body scan and requested more information than men. People with more knowledge about body scanners worried more about possible discrimination through body scanners. In trend, people more enthusiastic about technology had a more negative implicit attitude towards body scanners. Implicit and explicit attitudes did not correlate. The findings emphasize the importance of integrating different kinds of users in the design and development of security technologies to account for different opinions, needs and worries. Moreover, we suggest using knowledge that is gained in these kind of studies to train airport employees.

(C) 2016 The Authors. This is an open access article under the terms of the Creative Commons Attribution License 4.0, which allows use, distribution and reproduction in any medium, provided the original work is properly cited.

DOI: http://dx.doi.org/10.18533/rss.v1i5.33.

\subsection{Theory}

A few years ago the implementation of body scanners at airports was a controversial topic in the the media (e.g. Albrecht, 2008; Dauerer, 2010; Rubner, 2010), in Germany but also internationally. Politicians have tried to convince people that the implementation of body scanners would result in a clear increase in security (Bundesministerium des Innern, 2010) whereas ethicists voiced their concerns (e.g. Traut, Nagenborg, Rampp, \& Ammicht Quinn, 2010). Researchers asked the public about their opinion concerning body scanners (MitchenerNissen, Bowers, \& Chetty, 2012; Rajaonah et al., 2014). To our knowledge, however, the current literature lacks a 
study which examines what shapes people's attitudes. An understanding of variables predicting the attitude towards body scanners could help undertaking necessary steps to address those who report disapproval. Therefore, the aim of the present study is to gain more insights about people's attitude towards body scanners and to identify their predictors. Several models have been proposed to predict attitudes towards technology. One of the most well-known models is the Technology Acceptance Model (TAM), originally formulated by Davis (1989). It predicts the participant's intention to use a specific technology on the basis of the attitude towards this technology. Perceived usefulness and ease of use are assumed to be relevant predictors of the attitude in this model. However, for some technologies, usefulness and ease of use are either not essential or not sufficient to guarantee acceptance or a positive attitude (e.g. Beier, Spiekermann, \& Rothensee, 2006; Johnson, 2005; Morosan, 2012; Pikkarainen, Pikkarainen, Karjaluoto, \& Pahnila, 2004). Morosan (2012), for example, found that the TAM does not suffice to explain travelers' intention to use Biometric Systems. Consequently, he supplemented the TAM with logic predictors, which proved useful in his domain of research (perceived security, perceived privacy, and perceived innovativeness). It shows that, also for the context of body scanners, the TAM is not sufficient in predicting the attitude. The primary cause for this is probably the fact that body scanners are a security technology and that security technologies differ from other technologies in several ways (Schuler \& Wolkenstein, 2014): First, they address the need for security, which is - besides physiological needs - one of the basic needs in human life (Maslow, 1954). Furthermore, users do not use the technology themselves but it is applied to them, therefore, heteronomy has to be considered. In many cases, the government or organizations like airport operators implement security technologies. The intention is to protect people while observing them at the same time.

\subsection{Potential predictors of the attitude towards the use of body scanners}

To our knowledge, research that aims at predicting attitudes towards body scanners is very scarce. Therefore, the selection of predictors has to be based on research in related areas. It has been shown that socio-demographic variables influence several security technology related factors: For example, men are more interested in systems than women (Samson \& Huber, 2010). Studies exploring reactions to CCTV show that the infringement of privacy was rated higher by men than by women (Spriggs et al., 2005) and higher by younger than by older people (O'Donnell, Jetten, \& Ryan, 2010; Spriggs et al., 2005). Females regard the incident of a risky event more probable than men (Lerner et al., 2003). Thus, it can be assumed that gender and age are relevant factors impacting the attitude towards body scanners.

Personality traits have also been considered when investigating attitudes towards technology. For example, controlling convictions, i.e. feelings of self-efficacy related to technology (Beier, 1999), affect the intention to use Ubiquitous Computer applications. The intention of use can be assumed to be associated with acceptance or with a positive attitude towards these techniques (Beier et al., 2006). Hence, different approaches to technology appear to affect the access to and the handling of technology and probably also the attitude people have towards specific technologies.

Furthermore, there is a relationship between a person's knowledge about a specific technology and their attitude towards it (Costa-Font, Rudisill, \& Mossialos, 2008; Gaul et al., 2010). This has also been found to be valid for the attitude towards body scanners: People who received information about body scanners showed a more positive attitude towards it than people who did not receive information (Mitchener-Nissen et al., 2012).

It is also known that media consumption affects attitudes in the general public (Dietrich, Heider, Matschinger, \& Angermeyer, 2006). As body scanners have often been discussed in media (e.g. Albrecht, 2008; Dauerer, 2010; Rubner, 2010) one can assume that the amount of media consumption also affects the attitude towards body scanners.

\subsection{Implicit and explicit attitudes}

Typically attitudes are assessed with questionnaires or interviews. In the last years, however, the measure of explicit attitudes has been complemented by the measure of implicit attitudes. This fact can be traced back to the detection of two different ways of mental processing and the formulation of dual-process models (e.g. Gawronski \& Bodenhausen, 2006; Rydell \& McConnell, 2006; Strack \& Deutsch, 2004). These models assume that the two ways of mental processing result in two forms of attitudes (e.g. Wilson, Lindsey, \& Schooler, 2000): The reflective (Strack \& Deutsch, 2004) or propositional (Gawronski \& Bodenhausen, 2006) process leads to explicit attitudes whereas the impulsive (Strack \& Deutsch, 2004) or associative (Gawronski \& Bodenhausen, 2006) process leads to implicit attitudes. The reflective system requires more cognitive capacity and is influenced by distraction and arousal, whereas the impulsive system only requires low levels of cognitive capacity (Strack \& Deutsch, 2004). Both systems operate in parallel (Strack \& Deutsch, 2004) and thus may form different implicit and explicit attitudes simultaneously (Rydell \& McConnell, 2006; Wilson et al., 2000). Explicit attitudes change faster (fast learning system) whereas implicit attitudes are the product of a slow-learning system (Rydell \& McConnell, 2006). 
According to Gawronski \& Bodenhausen (2006) implicit attitudes are affective reactions that occur automatically. In the reflective system, behavior occurs on the basis of a decision process, therefore, knowledge about the topic and the consequences of the decision is integrated into the decision process (Strack \& Deutsch, 2004). Knowledge, as understood in this paper, is an accumulation of facts about the topic of body scanners. Consciously available information especially shapes explicit attitudes (Rydell, et al., 2006).

\subsection{Hypotheses}

The use of media is one form of knowledge acquirement. Thus, it can be assumed that the predictors knowledge and media consumption influence explicit attitudes.

For the other predictors no specific hypotheses can be formulated. Thus, the predictive power of age, gender and personality variables on the criteria implicit and explicit attitudes, as well as, the relationship between implicit and explicit attitudes will be explored.

In the following sections, we describe the operationalization of the variables we used to predict explicit and implicit attitudes about body scanners, as well as the assessment of the attitude itself. Afterwards, we present the results of the regression analyses. Finally, we discuss these results and possible implications they have on the current handling of body scanners.

\section{$2.0 \quad$ Methods and Materials}

\subsection{Participants}

The sample consists of 132 participants (50.76\% women) who were recruited through advertisements posted within the community. On average, they were 29.1 years $(S D=11.75)$ old and were all fluent in German.

\subsection{Predictors}

Personality variables

Technology affinity: To measure affinity towards technology we used the German scale technology affinity electronic devices (German: Technikaffinität - Elektronische Geräte, TA-EG, Karrer, Glaser, Clemens, \& Bruder, 2009), a questionnaire assessing four dimensions of technology affinity: enthusiasm toward electronic devices, subjective competence in using electronic devices, perceived positive consequences and perceived negative consequences. The questionnaire consists of 19 items; answers are given on a 5-point Likert-scale. Higher scores indicate greater affinity towards technology. The questionnaire addresses electronic devices such as computer, internet, cell phone, Palm/PDA, TV, hi-fi system, digital camera, Mp3 player, ATM and ticket machine or new systems, such as navigation in cars. With internal consistency values of Cronbach's $\alpha=.88$ (enthusiasm toward electronic devices), $\alpha=.85$ (subjective competence in using electronic devices), $\alpha=.64$ (perceived positive consequences) and $\alpha=.71$ (perceived negative consequences) the reliability of these subscales was satisfying in the current sample and comparable to the values reported by Pohlmeyer (2011) [Cronbach's $\alpha=.84$ (enthusiasm toward electronic devices), $\alpha=.86$ (subjective competence in using electronic devices), $\alpha=.77$ (perceived positive consequences) and $\alpha=.73$ (perceived negative consequences)].

Systemizing: Systemizing is defined as "the interest in systems, which includes analyzing, constructing, predicting, and controlling it" (Samson \& Huber, 2010, p.239). In this study, this construct was assessed by the short German version (Samson \& Huber, 2010) of the Systemizing Self-Assessment Scale which was developed on the basis of questionnaires from Baron-Cohen and colleagues (e.g. Baron-Cohen, Richler, Bisarya, Gurunathan, \& Wheelwright, 2003). It comprises 13 items and answers are given on a 4-point Likert-scale. A reliability analysis resulted in a sufficient Cronbach's $\alpha=.74$ which is comparable to that in the study of Samson \& Huber, (2010) with Cronbach's $\alpha=.82$.

\section{Knowledge}

To estimate how much participants know about body scanners, we formulated 13 (true or false statements) statements around the topic of body scanners, its functionality and its implementation (Table 1). Participants were asked to specify whether the statements were true, not correct or if they did not know it. Afterwards a sum score of correct answers was calculated. The reliability of this knowledge scale was Cronbach's $\alpha=.71$.

Table 1: Items from body scanner quiz

1. The body scanner underwent a practical test at the airport in Hamburg. Volunteers could test the body scanner there. 


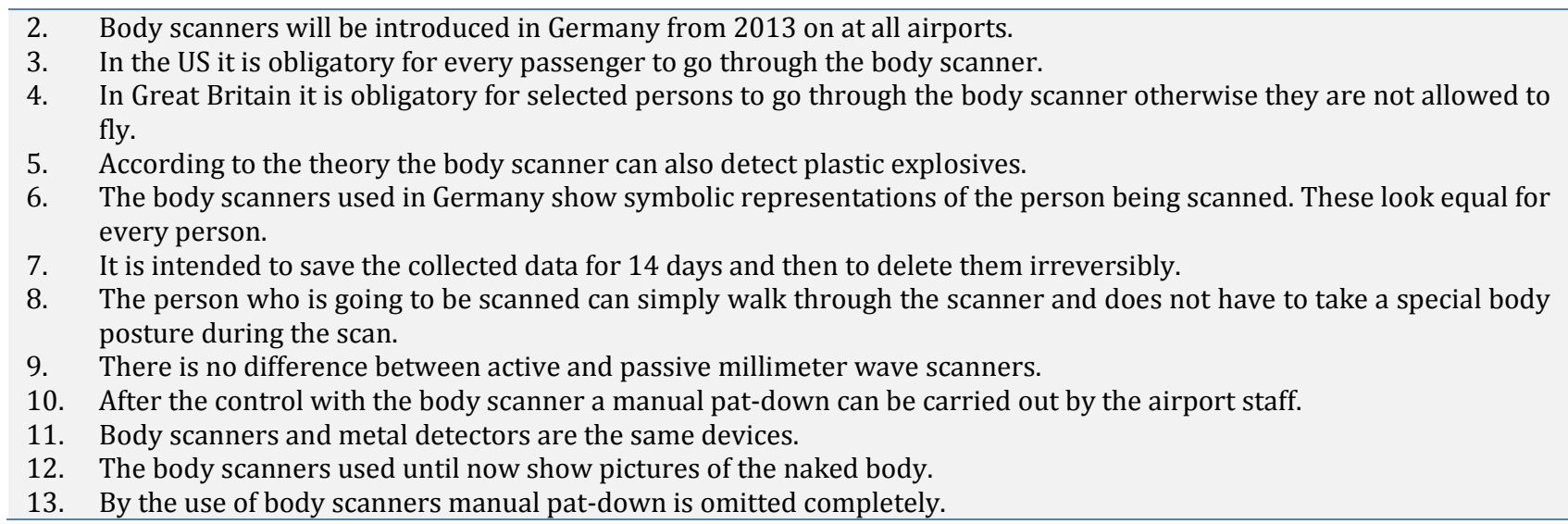

\section{Media consumption}

To estimate media consumption we asked three questions: How often they read printed newspapers ( 4 answering options: Never, 1-2 times per week, 3-4 times per week, daily), how often they watch TV (3 answering options: Less than 4 hours per day, ca. 4 hours per day, more than 4 hours per day) and how often they use the iternet outside of work ( 3 answering options: Less than 1.5 hours per day, ca. 1,5 hours per day, more than 1.5 hours per day).

\subsection{Criteria}

\section{Explicit attitude towards body scanners}

In a pre-study, we asked 30 participants to write down their thoughts on the topic of body scanners - their opinion, their fears or hopes, their expectations and concerns, their experiences and wishes. These statements were analyzed and clustered into categories (Pictogram/Picture of naked body, elucidation, humiliation, exposure/security, body dissatisfaction, privacy/data protection, good solution, discrimination, health, pat down, staff). Based on these categories, 41 statements were formulated and used to assess subjects' explicit attitudes towards body scanners in the present study.

First, participants were asked to imagine the following: They were going on a trip and therefore they were going to the airport, where they encountered the body scanners. They had to go through one of these body scanners to be allowed onto the plane. Then they were told that the experimenters were interested in learning which thoughts fill their mind and which thoughts they have regarding the control process with the body scanner. The 41 items were presented, and participants were asked to indicate on a 5-point Likert-scale to what extent each statement corresponded with their own attitude.

To determine the underlying factors of this questionnaire we conducted a principal axis factor analysis with oblique rotation (direct oblimin) on the 41 items. Factors were retained if they had an eigenvalue $>1.0$ (Kaiser's criterion). The Kaiser-Meyer-Olkin measure confirmed the adequacy of the sample for the analysis. Overall KMOStatistics was .88, for all individual variables KMO was $>.5$. Bartlett's test was highly significant $(<.001)$. The factor analysis revealed 9 factors with eigenvalues $>1.0$ and overall they explained $75 \%$ of the variance. Items and their factor loadings are depicted in Table 2. For each scale we checked the reliability. Factor 1 Worries about the effects of a body scan consisted of 11 items and showed high reliability (Cronbach's $\alpha=.95$ ). The higher the sum score of this scale, the more participants worried about the effects of a body scan, the more negative was their attitude. Factor 2 Positive Opinion about body scanners consisted of 7 items and also showed high reliability (Cronbach's $\alpha=.91$ ). The reliability increased, however, by deleting the item I think by the implementation of body scanners at security controls less discrimination occurs at the control. This decision was supported by the fact that this item did not fit quite well into the theoretical concept of the scale. Cronbach's $\alpha$ was $\alpha=.92$ after exclusion. The higher the sum score of this scale, the more positive is the attitude about body scanners. Factor 3 Feeling well informed about body scanners consisted of 5 items and had high reliability (Cronbach's $\alpha=.88$ ). The higher the sum score of this scale, the more positive was the opinion about the own state of knowledge, which means that participants felt well informed about body scanners. However, as this factor did not really represent an attitude it was excluded from further analyses. The higher the sum score of factor 4 Worries about data protection (3 items, Cronbach's $\alpha=.87$ ), the more people worried about their data, which represented a negative attitude. The same was true for factor 5 Worries about health issues ( 2 items, Cronbach's $\alpha=.79$ ), higher values reflected more worries and for factor 6 Dissatisfaction with the amount of information (2 items, Cronbach's $\alpha$ $=.82$ ), higher values indicated that people were not satisfied with the amount of information they received. The 
reliability of factor 7 Trust in body scan instead of airport staff, which consisted of 6 items, was not acceptable (Cronbach's $\alpha=.21$ ). Thus, we excluded factor 7 from further analysis. Factor 8 Worries about discrimination only consisted of one item. Higher values on this item reflect people's worries about discrimination through the use of body scanners. Factor 9 Harmlessness for the person being scanned consisted of 4 items, and the reliability was satisfying (Cronbach's $\alpha=.73$ ). The higher the sum score for this factor, the more harmless participants perceived the body scanner to be for the scanned person, which means the more positive was their attitude.

Table 2: Summary of exploratory factor analysis results for the questionnaire ,Expectations about body scanning' $(\mathrm{N}=131)$ Items

\section{Rotated Factor Loadings}

Factor 1

Worries about the effects of a body scan

34. I fear that I do like my body less after the body scan.

6. I fear that I am more dissatisfied with my body after the body scan.

19. I think that I will be ashamed of my body when I go through the body scanner.

30. I fear that someone could make fun of me when I go through the body scanner.

7. I fear that I am in a worse temper after the body scan.

23. I worry if the airport staff is going to make jokes about my picture.

35. I do not think that I am going to be ashamed when I go through the body scanner.

33. I fear that my mood will be worse after the body scan than before.

38. I think that I am going to feel abased when I go through the body scanner.

4. I think that I am going to be ashamed when I go through the body scanner.

41. I worry if the airport staff is going to make unpleasant comments.

Eigenvalue

$\%$ of variance

Cronbach's $\alpha$

20. I think that through the use of body scanners at airports attacks can be prevented.

5. I think that the use of body scanners at the airport increases the security.

31. I do not think that through the use of body scanners at airports attacks can be prevented.

17. I don not think that the use of body scanners at airports increases the security.

37. I have a positive opinion about the body scanner.

11. I would prefer to be patted down by the airport staff than to go through the body scanner.

25. I think through the introduction of the body scanner at airports there is going to be less discrimination at the control.

Eigenvalue

$\%$ of variance

Cronbach's $\alpha$

15. I think I am well informed about the mode of operation of the body scanner.

22. I think I am well informed about the process of a body scan.

2. I think I am well informed about the body scanner.

28. I am well informed about how the body scanner affects the body.

39. I think I am well informed about the reasons of the implementation of the body

scanner.

Eigenvalue

$\%$ of variance

Cronbach's $\alpha$

Note. Item 25 is crossed out because it reduced the internal consistency of factor 2 . Factors are crossed out because they did not represent an attitude in terms of content (factor 3) or the internal consistency was not acceptable (factor 7).

Table 2 (continued): Summary of exploratory factor analysis results for the questionnaire, Expectations about body scanning' $(\mathrm{N}=131)$

\section{Items}

24. I worry if my data are going to be handed over.

21. I worry how my personal data is going to be treated.

40. I do not worry I how my personal data is going to be treated.

Eigenvalue

$\%$ of variance

Cronbach's $\alpha$

10. I think my health is not going to be impaired through the control with a body scan.

32. I fear the walk through the body scanner is bad for my health.

Eigenvalue

915

.900

.826

.672

.628

.624

$-.548$

.545

.540

.535

.483

14.40

35.13

.95

Factor 2

Positive Opinion about body scanners

.912

.894

$-.816$

$-.803$

.569

$-375$

.355

4.19

10.23

.92

Factor 3

Feeling well informed about body seanners

.950

.844

.828

.680

.574

3.90

9.51

.88 


\begin{tabular}{|c|c|}
\hline $\begin{array}{l}\% \text { of variance } \\
\text { Cronbach's } \alpha\end{array}$ & $\begin{array}{l}3.46 \\
.79 \\
\text { Factor } 6 \\
\text { Dissatisfaction with the amount of } \\
\text { information }\end{array}$ \\
\hline $\begin{array}{l}\text { 14. I wish I would have received more information in advance about the body scanner } \\
\text { through the politics. }\end{array}$ & .839 \\
\hline $\begin{array}{l}\text { 18. I wish I would have received more information in advance about the body scanner } \\
\text { through the media. }\end{array}$ & .815 \\
\hline Eigenvalue & 1.32 \\
\hline$\%$ of variance & 3.21 \\
\hline Cronbach's $\alpha$ & 82 \\
\hline 26. I worry if the airport staff is trustworthy. & $\begin{array}{l}\text { Trust in body sean instead of airport staff } \\
.403\end{array}$ \\
\hline 13. I worry if the airport staff is well trained. & 389 \\
\hline 9. I have a positive feeling when I imagine being controlled with a body scanner. & 358 \\
\hline $\begin{array}{l}\text { 29. I think the airport staff is going to conduct the control with the body scanner } \\
\text { professionally. }\end{array}$ & .350 \\
\hline 12. I am totally relaxed when I think at the control with the body scanner. & 315 \\
\hline 1. I am totally unconcerned about the coming security control. & 309 \\
\hline Eigenvalue & 1.23 \\
\hline$\%$ of variance & 3.00 \\
\hline Cronbach's $\alpha$ & .21 \\
\hline
\end{tabular}

Table 2 (continued): Summary of exploratory factor analysis results for the questionnaire ,Expectations about body scanning' $(\mathrm{N}=131)$

\section{Items}

Rotated Factor Loadings

Factor 8

Worries about discrimination

36. I think through the introduction of body scanners at security controls there is going to be less discrimination at the control.

Eigenvalue .537

$\%$ of variance

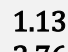

2.76

Factor 9

Harmlessness for the person being scanned

27. I do not worry about my privacy.

16. I worry about my privacy.

.621

$-.452$

8. I think I would not mind if the body scan would be conducted by a person of the other $\quad .363$ gender.

3. I think that body scanners were developed in a manner that people with physical specialties as for example disabilities or breast implants do not experience any disadvantage through the scan.

$\begin{array}{ll}\text { Eigenvalue } & 1.01 \\ \text { \% of variance } & 2.47 \\ \text { Cronbach's } \alpha & .73\end{array}$

Note. Item 25 is crossed out because it reduced the internal consistency of factor 2. Factors are crossed out because they did not represent an attitude in terms of content (factor 3) or the internal consistency was not acceptable (factor 7).

\section{Implicit attitude about body scanners}

Implicit Attitudes are responsible for implicit, uncontrollable reactions or when people act in a way that they do not see as an attitude expression and therefore do not control their reactions (Wilson et al., 2000). Implicit attitudes do not rely on a specific origin and are automatically activated, which means that people cannot argue why they have these specific implicit attitudes. According to Strack \& Deutsch (2004) elements in the impulsive systems are connected through associative links. This principle is used in the Implicit Association Test (IAT, Greenwald, McGhee, \& Schwartz, 1998). To measure the implicit attitude about body scanners, we used a special form of the IAT, the Single Target Implicit Association Test (ST-IAT; (e.g. Bluemke \& Friese, 2008; Wigboldus, Holland, \& van Knippenberg, 2004). According to the advice of Bluemke \& Friese (2008), we conducted a prestudy to measure the relationship between the target dimension body scanner and the correspondent stimuli and their valence. The pre-requisites for the target-stimuli in the ST-IAT are that the association to the concept body scanner is high but the valence of the stimuli should be neither positive nor negative but neutral. Therefore, we collected pictures and terms related to the dimension body scanner. Thirty participants (16 female) took part in this pre-study. Mean age of the participants was $33.53(S D=9.68)$ years. Participants were presented with 3 
pictures and 11 terms. First they had to rate the valence of the stimuli on a 9-point Likert-scale $(1=$ very negative, $9=$ very positive). Then they had to rate the same stimuli according to their association to the dimension body scanner on a 9-point Likert-scale $(1=$ no association, $9=$ very high association). Results of the pre-study are depicted in Figure 1. Based on the results, we chose the words security control and airport, as well as the pictures of the pictogram, the body scanner and the plane to be used in the ST-IAT. The process of the ST-IAT is described in Figure 2. The attribute stimuli were adopted from Bluemke \& Friese (2008). The inter-stimulus interval was 300 milliseconds. Twenty stimuli were presented in the practice blocks. As Bluemke \& Friese (2008) suggest, reliability can be improved if more trials are presented in the combined blocks. According to Kämpfe et al., (2009) we implemented 60 trials in the combined blocks. The presentation of the stimuli was randomized. To avoid order effects, the target dimension body scanner was first combined with the attribute dimension negative in the combined block for half of the participants, whereas it was combined with the attribute dimension positive for the other half. The ST-IAT was presented with Inquisit (Millisecond Software, 2012). To analyze the ST-IAT we used D-score resulting from the improved scoring algorithm of Anthony G Greenwald, Nosek, and Banaji (2003). The mean latency of the body scanner + positive-trial was subtracted from the body scanner + negative-trial (Bluemke \& Friese 2008). Higher scores indicated a more positive implicit attitude.

Figure 1: Results of the ST-IAT pre-study.

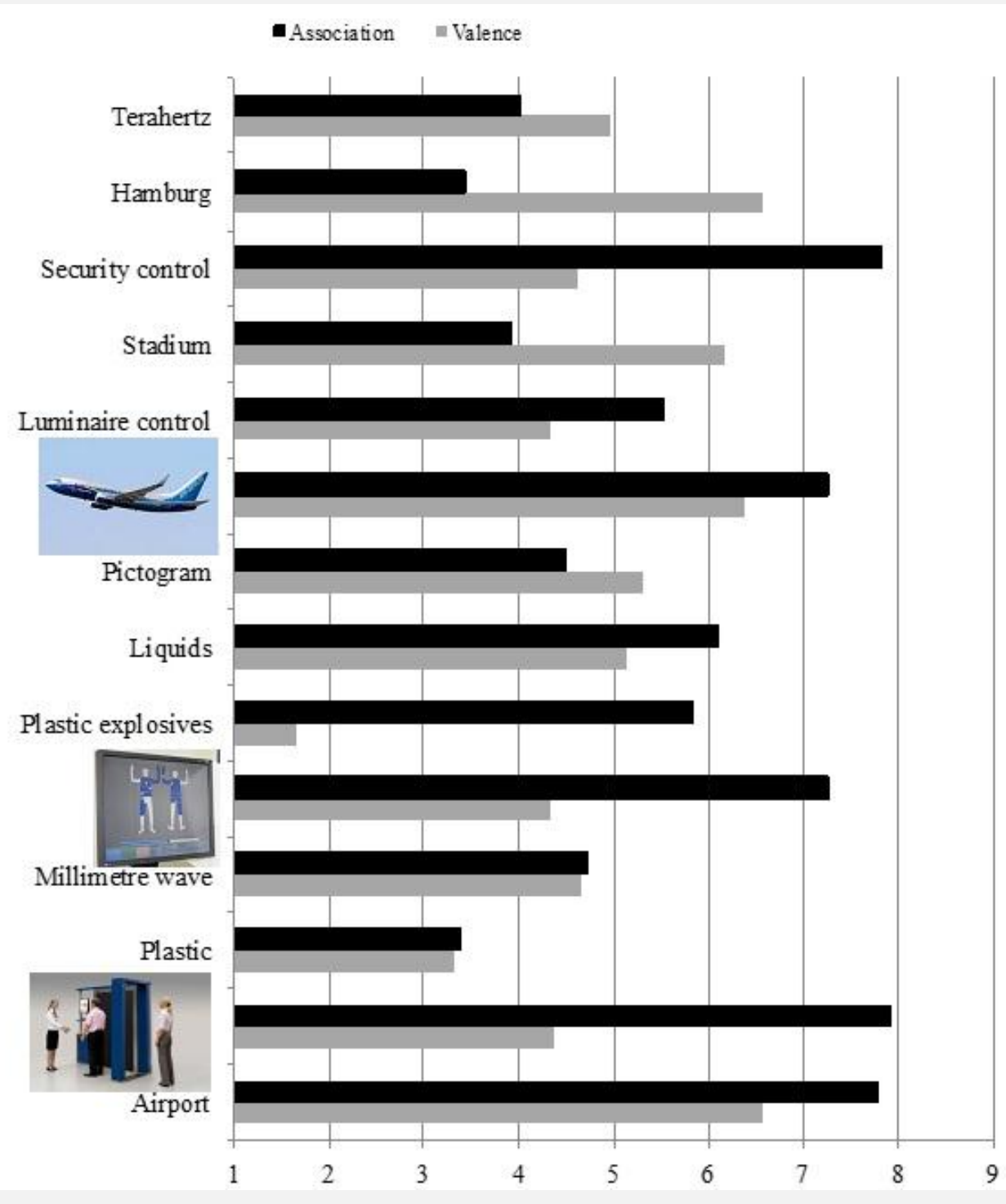

Figure 2: Structure of the ST-IAT. 


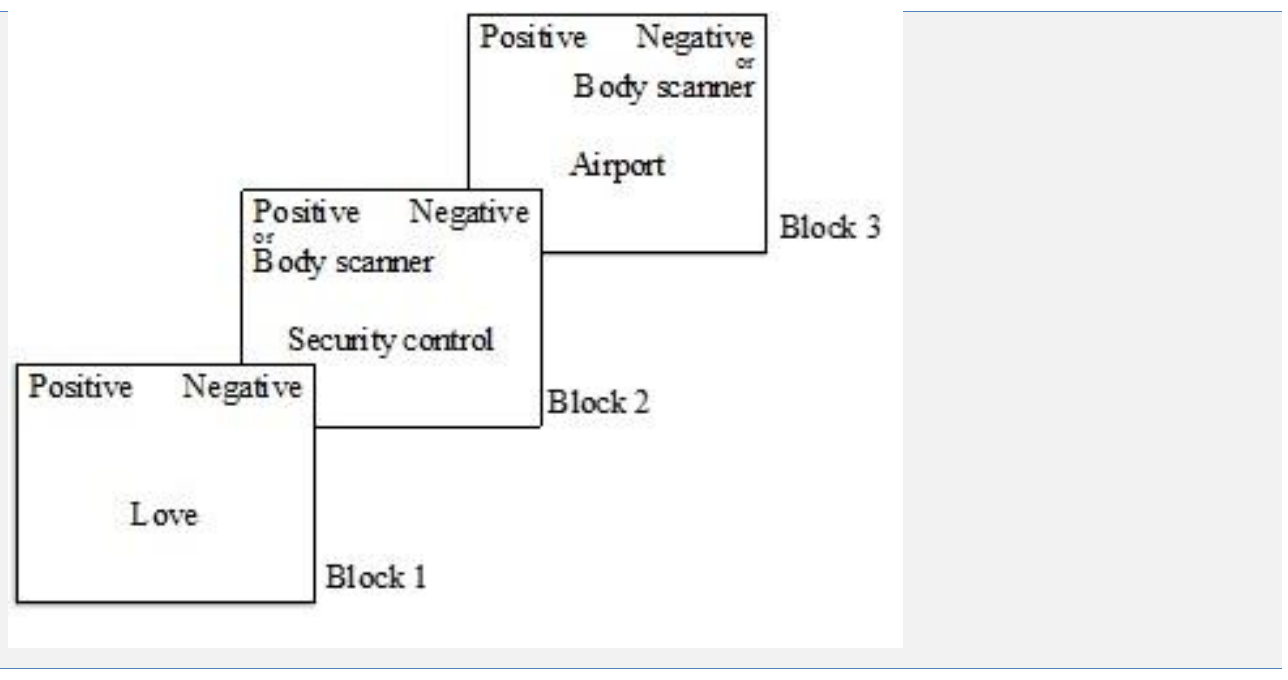

The ST-IAT operationalizes the implicit attitude by calculating reaction times representing association strengths. In contrast to the conventional IAT (Anthony G. Greenwald \& Farnham, 2000) the ST-IAT only consists of one target category. For the Body scanner ST-IAT used in this study, we used the target category Body scanner. It consists of the words security control and airport as well as of pictures of a pictogram, a body scanner and a plane. Beside the target category the ST-IAT comprises the attribute categories Positive and Negative. We used the same stimuli as Bluemke \& Friese (2008). The negative category included the words: stink, poison, catastrophe, disease and pain. The positive category included the words joy, present, love, health and laughter. The ST-IAT was conducted in three major blocks. In the first block, participants had to sort the stimuli of the attribute categories. Therefore the names of both categories were placed on the top of the screen. Participants used two keys (E, I) to sort the terms (appearing at the center of the screen) to the correspondent category. This block consisted of 20 trials. The second block was arranged according to Block 1, with the exception that the target category was added to one of the attribute categories, and they shared one response key. Participants now had to sort stimuli of the attribute categories and the target category. This block was divided into a practice block (20 trials) and a test block (60 trials). The third block followed the same structure as the second block with the exception that the target category was combined with the other attribute category. The two combined blocks are the critical blocks relevant for the analysis. We compared whether participants reacted faster if Body scanner and Positive were combined than if Body scanner and Negative were combined.

\subsection{Procedure}

Participants first conducted the ST-IAT. Then they filled out the questionnaires in the following order: Personality variables, explicit attitude about body scanner, knowledge, socio-demographic variables and media consumption.

\subsection{Statistics}

We conducted nine regression analyses with gender, age, knowledge, technological affinity, systemizing, and media consumption as predictors and the explicit and the implicit attitudes as criterions, respectively. Our objective was to test the whole model, as well as the individual predictors. We selected the ENTER method and included the predictors in four steps. In the first step, we included the demographic variables gender and age. In the next step, we entered the variable knowledge to the model. After that, the personality variables were included, i.e. the four subscales of the $T A-E G$ and the systemizing scale. As a last step, we entered the media consumption variables (three items). In sum, the model consisted of 11 predictors. We ran separate regression analysis for the eight factors of the explicit attitude and the implicit attitude. We chose to exclude cases listwise, resulting in a sample of 121 participants for all regression analyses. The relationship between implicit and explicit attitudes was assessed through Pearson's correlation coefficient, $r^{2}$.

\subsection{Results}

\subsection{Prediction of explicit attitude}

All relevant results of the regression analyses are depicted in Table 3. We found a significant predictor for factor 1 Worries about the effects of a body scan. Model 1, 2 and 3 reached significance. We adopted Model 1, F(2,118) $=6.98, p<.01$ as the increases in $R^{2}$ from Model 1 to Model 2 and from Model 2 to Model 3 did not become significant. Model 1 explained $10.6 \%$ of factor 1 (worries about the effects of a body scan). The adjusted $R^{2}$ 
(adjusted $R^{2}=.09$ ) was very close to $R^{2}$, meaning that the model generalized very well. In Model 1 the predictor gender became significant, $t(118)=-3.42, p<.01$, indicating that women worried more about the effects of a body scan than men.

Also for factor 6 Dissatisfaction with the amount of information we found a significant predictor. Model 1, 2 and 3 reached significance. The model summary showed that only $R^{2}$ of Model 1 got significant. Therefore we adopted Model $1, F(2,118)=5.27, p<.01$, which explained $8.2 \%$ of factor 6 (Dissatisfaction with the amount of information). The adjusted $\mathrm{R}^{2}$ (adjusted $R^{2}=.07$ ) is very close to $R^{2}$, meaning that the model generalized very well. In Model 1 the predictor gender, $t(118)=-3.01, \mathrm{p}<.01$ became significant. Women felt rather unsatisfied with the amount of information they received and requested more for information than men.

The third factor we found a significant predictor for was factor 8 Worries about discrimination. Model 2 reached significance, $\mathrm{F}(3,117)=3.39, \mathrm{p}<.05$. The model summary showed that the increase in $R^{2}$ from model 1 to model 2 got significant. Model 2 explained $2.9 \%$ of factor 8 (worries about discrimination). The adjusted $R^{2}$ (adjusted $\left.R^{2}=.01\right)$ was close to $R^{2}$, meaning that the model generalized very well. In Model 2 the predictor knowledge, $\mathrm{t}(117)=2.16, \mathrm{p}<.05$ became significant. People who knew more about the body scanner worried more about possible discrimination through a body scan.

We were not able to find significant predictors for factor 2 Positive Opinion about body scanners, factor 4 Worries about data protection, factor 5 Worries about health issues and factor 9 Harmlessness for the person being scanned. None of the models of these factors reached significance.

Table 3: Model descriptions of the regression analyses

\begin{tabular}{|c|c|c|c|c|c|}
\hline \multicolumn{6}{|c|}{ Criterion: Factor 1 Worries about the effects of a body scan } \\
\hline & & Model 1 & Model 2 & Model 3 & Model 4 \\
\hline$F a$ & & $6.98^{* *}$ & $4.80^{* *}$ & $2.09 *$ & 1.6 \\
\hline$R$ & & .33 & .33 & .36 & .38 \\
\hline$R^{2}$ & & .11 & .11 & .13 & .14 \\
\hline$\Delta R^{2}$ & & .11 & .00 & .02 & .01 \\
\hline$\Delta F^{b}$ & & $6.98^{* *}$ & .50 & .53 & .44 \\
\hline & & del 1 & & & \\
\hline & & $S E B$ & $\beta$ & & \\
\hline Constant & & 2.90 & $.00^{* * *}$ & & \\
\hline $\begin{array}{l}\text { Step 1: } \\
\text { variables }\end{array}$ & Demographic & & & & \\
\hline Gender & & -.54 & $.00^{* *}$ & & \\
\hline Age & & -.01 & -.09 & & \\
\hline Criterion: $F$ & tor 2 Positive $O_{1}$ & n about body scan & & & \\
\hline & & Model 1 & Model 2 & Model 3 & Model 4 \\
\hline$F^{a}$ & & 1.48 & 1.06 & 1.17 & 1.36 \\
\hline$R$ & & .16 & .16 & .28 & .35 \\
\hline$R^{2}$ & & .02 & .03 & .08 & .12 \\
\hline$\Delta R^{2}$ & & .02 & .00 & .05 & .04 \\
\hline$\Delta F^{b}$ & & 1.48 & .25 & 1.22 & 1.82 \\
\hline Criterion: $\mathrm{F}$ & tor 4 Worries al & data protection & & & \\
\hline & & Model 1 & Model 2 & Model 3 & Model 4 \\
\hline$F a$ & & .40 & .58 & 1.27 & 1.13 \\
\hline$R$ & & .08 & .12 & .29 & .32 \\
\hline$R^{2}$ & & .01 & .02 & .08 & .10 \\
\hline$\Delta R^{2}$ & & .01 & .01 & .07 & .02 \\
\hline$\Delta F^{b}$ & & .40 & .95 & 1.67 & .78 \\
\hline Criterion: $\mathrm{F}$ & tor 5 Worries al & health issues & & & \\
\hline & & Model 1 & Model 2 & Model 3 & Model 4 \\
\hline$F^{a}$ & & .99 & 1.48 & 1.87 & 1.46 \\
\hline$R$ & & .13 & .19 & .34 & .36 \\
\hline$R^{2}$ & & .0 & .04 & .12 & .13 \\
\hline$\Delta R^{2}$ & & .02 & .02 & .08 & .01 \\
\hline$\Delta F^{b}$ & & .99 & 2.44 & 2.05 & .47 \\
\hline
\end{tabular}

Table 3 (continued): Model descriptions of the regression analyses

Criterion: Factor 6 Dissatisfaction with the amount of information




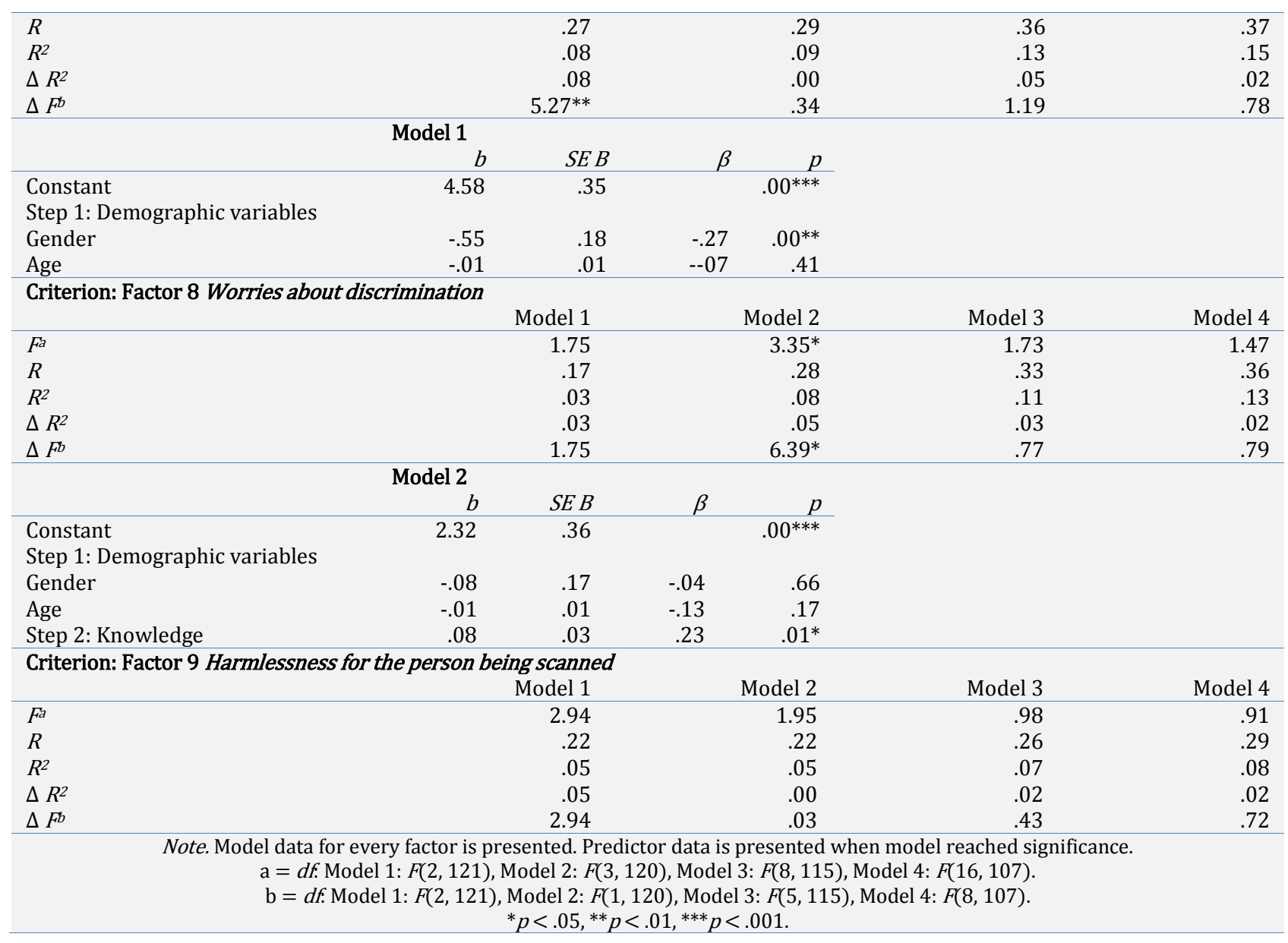

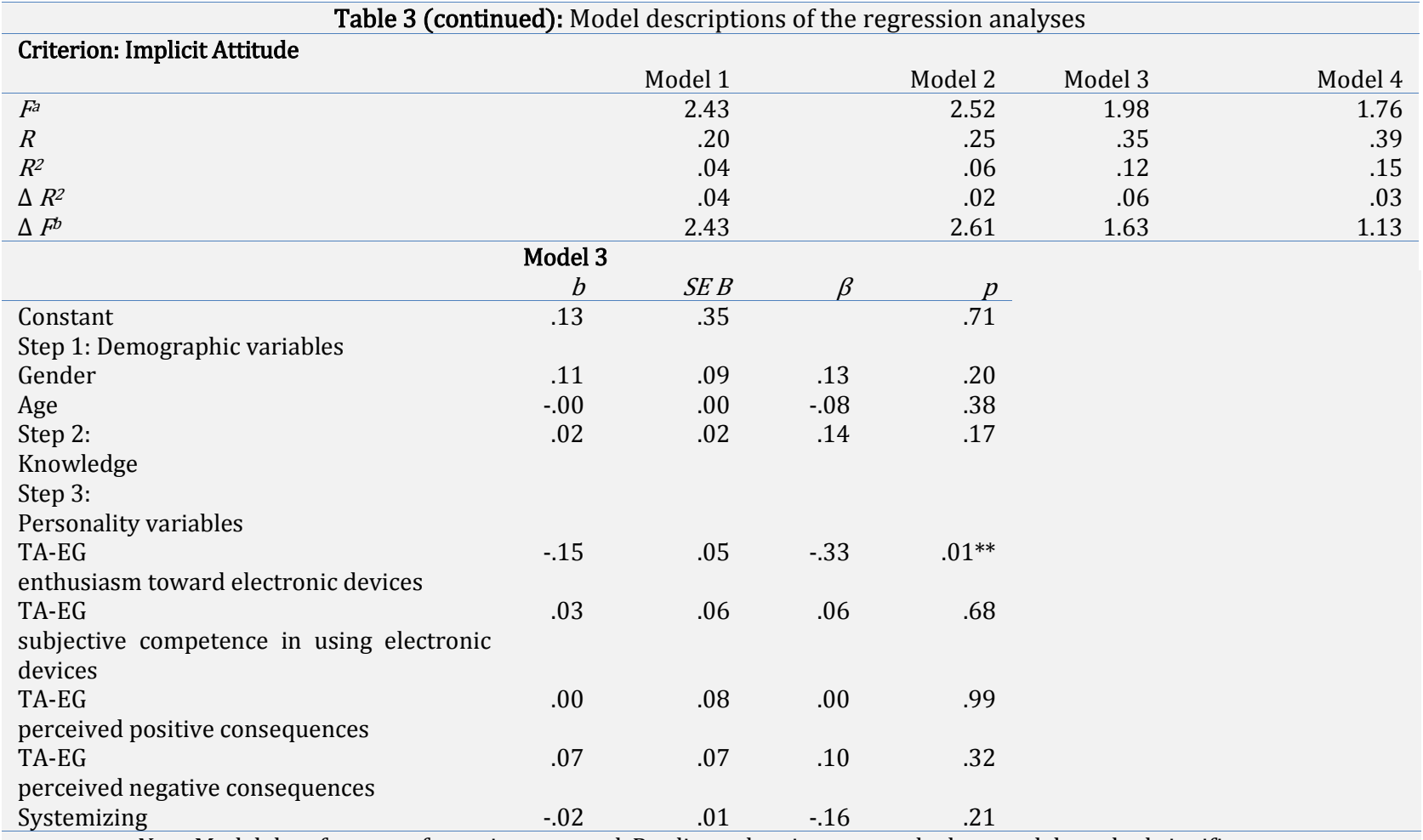

Note. Model data for every factor is presented. Predictor data is presented when model reached significance.

$\mathrm{a}=d f$ Model 1: $F(2,121)$, Model 2: $F(3,120)$, Model 3: $F(8,115)$, Model 4: $F(16,107)$.

$\mathrm{b}=d f$. Model 1: $F(2,121)$, Model 2: $F(1,120)$, Model 3: $F(5,115)$, Model 4: $F(8,107)$.

${ }^{*} p<.05,{ }^{* *} p<.01,{ }^{* * *} p<.001$.

3.02 Prediction of implicit attitude 
For the implicit attitude as outcome variable, none of the models reached significance, although model 3 was marginally significant: $F(8,112)=1.98, p=.055$. In Model 3 the predictor enthusiasm toward electronic devices (TA-EG subscale), $t(112)=-2.65, p<.05$ became significant. People who are more enthusiastic about technology have a a worse implicit attitude towards body scanners. Model 3 explained $12.4 \%$ of the variance of the implicit attitude about body scanners with an adjusted $R^{2}=.06$ which signalizes a rather bad generalization of the model.

\subsection{Correlation between implicit and explicit attitude}

None of the correlations was significant (all $p>.07$ ).

\subsection{Discussion}

The aim of the present study was to gain more insights into factors affecting people's attitude towards body scanners. The more we know about relevant factors in this area, the better we are able to investigate ways to implement the technology in a more comfortable manner for technology users. Therefore, we investigated whether the predictors gender and age, the personality variables technological affinity and systemizing, the amount of knowledge about body scanners and the amount of media consumption, can be used to predict explicit and implicit attitudes towards body scanners. Furthermore, we investigated whether there is a relationship between implicit and explicit attitudes towards body scanners.

A factor analysis revealed nine factors underlying the attitudes of people towards body scanners, of which, seven were used as criteria in the following regression analyses. Gender predicted worries about the effects of a body scan, in that women worried more about the effects of a body scan than men. The worries about the effect of a body scan strongly refer to how people see their body after the scan, if they felt uncomfortable or ashamed. This factor relates to body perception and the relationship to one's own body. The result that women worry more about the effects of a body scan than men is not surprising, given that women are generally more concerned about their weight and shape (Connors \& Casey, 2006), more dissatisfied with their body and their weight (Pingitore, Spring \& Garfieldt, 1997) and their satisfaction with their figure more strongly relates to their self-esteem (Abell \& Richards, 1996).

We asked participants if they felt the need for more information (dissatisfaction with the amount of information). Again, gender turned out as a significant predictor. Women requested more information than men. On the one hand, this finding is surprising because it was shown for instance that women are less critical towards CCTV concerning the invasion to privacy (Spriggs et al., 2005) and estimate the probability of risky events higher than men (Lerner et al., 2003). These studies could have led to the assumption that women tend to be more accessible to arguments in favor of security technology and are thus less critical. On the other hand women and men have different types of knowledge about technology in general. Women did not have the same understanding of technology as men, as they scored lower in systemizing thinking (Samson \& Huber, 2010). Therefore, it is reasonable to assume that they need more information to feel well informed.

Knowledge was a significant predictor of people's worries about discrimination. The more knowledge people have about body scanners the more they are worried about discrimination. This result contradicts findings of Mitchener-Nissen et al. (2012) showing that the more people know about body scanners, the more positive is their attitude. Our results suggest that knowledge makes people more critical. The research of Costa-Font et al. (2008) about nuclear power revealed similar results. People do not only get information about the security aspects of body scanners (e.g. Bundesministerium des Innern, 2010), but also hear critical voices concerning body scanners (e.g. Bello-Salau, Salami, \& Hussaini, 2012; Nagenborg, 2011; Traut et al, 2010). It seems likely that people who are better informed have more knowledge about effects of body scanners beyond increasing security as, for example, regarding religious concerns (Bello-Salau et al., 2012) or regarding the disclosure of disabilities or artificial limbs without the agreement of the respective persons (Traut et al., 2010).

Concerning implicit attitudes the model only reached marginal significance. We thus have to point out that our discussion of the results only relies on a statistical trend and the results and their implications should be interpreted with caution. If we consider this model, then the predictor enthusiasm toward electronic devices (TAEG subscale) predicts the implicit attitude. People who are more enthusiastic about technology have a more negative implicit attitude towards body scanners. Personality variables likely regulate how people approach technology via the perception of approach and avoidance (Strack \& Deutsch, 2004). As enthusiasm can be described as a positive emotion towards technology, it seems likely to predict the implicit attitude as this is also an affective reaction (Gawronski \& Bodenhausen, 2006). Interestingly, participants with more enthusiasm about electronic devices displayed more negative implicit attitudes. It may be assumed that people enthusiastic about electronic devices like using them but mistrust technology when they have no control over it. 
In summary, our first hypothesis was confirmed as knowledge predicted worries about discrimination. Our second hypothesis was rejected, as media consumption did not predict the attitude towards body scanners. Ditton, Chadee, Farrall, Gilchrist, and Bannister (2004) not only conducted a quantitative measure, the authors also analyzed the data qualitatively and found that it is not the amount of media consumption that matters but it is how relevant people interpret the media content. This should be considered in future studies. Gender significantly predicted worries about the effects of a body scan and dissatisfaction with the amount of information. Age did not have any predictive effect. In trend enthusiasm toward electronic devices predicted the implicit attitude. Finally, we did not find a significant correlation between implicit and explicit attitude. Thus, our results support dualattitude models, suggesting that different implicit and explicit attitudes can persist because they are formed differently.

\subsection{Limitations}

Despite interesting results, our study is subject to some limitations. First, the sample size was restricted. Future studies should confirm the results using a larger sample. Second, for both criteria we had to develop measurements, as there were no pre-existing measures. We did this with great diligence. The development of the explicit attitude measure was based on statements of participants of a former body scanner-study. Thus, we can ensure that these statements are of general relevance. The ST-IAT was based on a pre-study where we validated the stimulus material. Nevertheless, both methods will have to be used in other studies and also the convergent validity of the procedures will have to be investigated.

\subsection{Policy Implications and Conclusions}

The current study demonstrates that gender, knowledge and enthusiasm toward electronic devices have predictive power concerning the attitude towards body scanners. It revealed that people react differently to the idea of the implementation and use of body scanners. Women demonstrate more worries when imagining being scanned and they do not feel well informed through media or politics. It also became obvious that people who are better informed about body scanners are more preoccupied with possible discrimination through the use of body scanners. The fact that we did not find a correlation between implicit and explicit attitudes suggests that other mechanisms than rationality may be at work when dealing with body scanners and that unconscious processes also regulate how people approach this topic.

Based on the specific results we suggest to keep in mind that the use of body scanners may trigger worries in people (in this case especially women) that can be related to the influence of a body scan on personal body perception (see also Laib \& Wolkenstein, submitted). Similarly as Morosan (2012) we encourage responsible persons like politicians or airport providers to provide people with realistic and sufficient information. We recommend training airport employees accordingly. They should be aware of the fact that people might feel uncomfortable being scanned and that giving them unbiased and clear information might have a calming effect. Furthermore, they should be provided with sufficient information about body scanners and be prepared to reply to questions or uncertainties of the passengers. To identify and consider unconscious processes we suggest to also implement alternative methods like the IAT to evaluate security technologies (Schuler \& Wolkenstein, 2014).

The attempts of the German government to reduce difficulties when introducing body scanners and to address ethical concerns appeared ineffective and resulted in efforts such as changing the designation from "body scanner" to "security scanner". All attempts to increase the support of body scanners in the general public happened rather post hoc and as a reaction to difficulties. A better beforehand understanding of what people think about body scanners might have resulted in a more considerate implementation. One way to do this is described in the present study. In general the findings emphasize the importance of integrating different kinds of people (different gender, different knowledge etc.) in the design and development process of security technologies to account for different opinions, needs and worries. As developers cannot put themselves in the position of so many different personalities participation of users in the design and development process seems reasonable. 


\section{References}

Abell, S. C., \& Richards, M. H. (1996). The Relationship between Body Shape Satisfaction and Self-Esteem: An Investigation of Gender and Class Differences. Journal of Youth and Adolescence, 25(5), 691-703. http://dx.doi.org/10.1007/BF01537361.

Albrecht, H. (2008, 30.10.2008). Angst vor der Blöße - Die Ablehnung von Ganzkörperscannern hat auch mit Scham zu tun. DIE ZEIT online. Retrieved from http://www.zeit.de/2008/45/Scham/seite-1.

Baron-Cohen, S., Richler, J., Bisarya, D., Gurunathan, N., \& Wheelwright, S. (2003). The systemizing quotient: an investigation of adults with Asperger syndrome or high-functioning autism, and normal sex differences. Philosophical Transactions of the Royal Society of London. Series B: Biological Sciences, 358(1430), 361-374. http://dx.doi.org/10.1098/rstb.2002.1206.

Beier, G. (1999). Kontrollüberzeugungen im Umgang mit Technik. Report Psychologie, 684-693.

Beier, G., Spiekermann, S., \& Rothensee, M. (2006). Die Akzeptanz zukünftiger Ubiquitous Computing Anwendungen. In A. M. Heinecke \& H. Paul (Eds.), Mensch \& Computer 2006: Mensch und Computer im StrukturWandel (pp. 145-154). München: Oldenbourg Verlag.

Bello-Salau, H., Salami, A. F., \& Hussaini, M. (2012). Ethical Analysis of the Full-Body Scanner (FBS) for Airport Security. Advances in Natural and Applied Sciences, 6(5), 664-672.

Bluemke, M., \& Friese, M. (2008). Reliability and Validity of the Single-Target IAT (ST-IAT): Assessing Automatic Affect towards Multiple Attitude Objects. European Journal of Social Psychology, 38(6), 977-997. http://dx.doi.org/10.1002/ejsp.487

Bundesministerium des Innern. (2010). "Der Sicherheitsgewinn ist eindeutig" - Interview mit Herrn Prof. Dr. Klaus Thoma, Fraunhofer Institut für http://www.bmi.bund.de/SharedDocs/Interviews/DE/2010/09/thoma_koerperscanner.html.

Bundesministerium des Innern. (2010). Start des Probebetriebs für den Körperscanner. Retrieved from http://www.bmi.bund.de/SharedDocs/Pressemitteilungen/DE/2010/mitMarginalspalte/09/koerperscan ner.html

Connors, J., \& Casey, P. (2006). Sex, Body-Esteem and Self-Esteem. Psychological Reports, 98(3), 699-704. http://dx.doi.org/10.2466/pr0.98.3.699-704

Costa-Font, J., Rudisill, C., \& Mossialos, E. (2008). Attitudes as an Expression of Knowledge and "Political Anchoring": The Case of Nuclear Power in the United Kingdom. Risk Analysis, 28(5), 1273-1288. http://dx.doi.org/10.1111/j.1539-6924.2008.01094.x

Dauerer, A. (2010). Lückenlose Durchleuchtung. Focus Online. Retrieved from http://www.focus.de/reisen/flug/tid16743/koerperscanner-lueckenlose-durchleuchtung_aid_468120.html

Davis, F. D. (1989). Perceived Usefulness, Perceived Ease of Use, and User Acceptance of Information Technology. MIS quarterly, 319-340. http://dx.doi.org/10.2307/249008.

Dietrich, S., Heider, D., Matschinger, H., \& Angermeyer, M. C. (2006). Influence of Newspaper Reporting on Adolescents' Attitudes toward People with Mental Illness. Social Psychiatry and Psychiatric Epidemiology, 41(4), 318-322. http://dx.doi.org/10.1007/s00127-005-0026-y

Ditton, J., Chadee, D., Farrall, S., Gilchrist, E., \& Bannister, J. (2004). From Imitation To Intimidation. British Journal of Criminology, 44(4), 595-610. http://dx.doi.org/10.1093/bjc/azh028.

Gaul, S., Ziefle, M., Wilkowska, W., Arning, K., Kasugai, K., Röcker, C., \& Jakobs, E.-M. (2010). Technikakzeptanz als integraler Bestandteil der Entwicklung medizintechnischer Produkte. Paper presented at the Deutscher AALKongress Berlin.

Gawronski, B., \& Bodenhausen, G. V. (2006). Associative and Propositional Processes in Evaluation: An Integrative Review of Implicit and Explicit Attitude Change. Psychological Bulletin, 132(5), 692-731. http://dx.doi.org/10.1037/0033-2909.132.5.692

Greenwald, A. G., \& Banaji, M. R. (1995). Implicit Social Cognition: Attitudes, Self-Esteem, and Stereotypes. Psychological Review, 102(1), 4-27. http://dx.doi.org/10.1037/0033-295X.102.1.4

Greenwald, A. G., McGhee, D. E., \& Schwartz, J. L. K. (1998). Measuring Individual Differences in Implicit Cognition: The Implicit Association Test. Journal of Personality and Social Psychology, 74(6), 1464-1480. http://dx.doi.org/10.1037/0022-3514.74.6.1464

Greenwald, A. G., Nosek, B. A., \& Banaji, M. R. (2003). Understanding and Using the Implicit Association Test: I. An Improved Scoring Algorithm. Journal of Personality and Social Psychology, 85(2), 197. http://dx.doi.org/10.1037/0022-3514.85.2.197

Greenwald, A. G., \& Farnham, S. D. (2000). Using the implicit association test to measure self-esteem and selfconcept. Journal of personality and social psychology, 79(6), 1022.

Johnson, A. M. (2005). The Technology Acceptance Model and the Decision to Invest in Information Security. Paper presented at the Southern Association of Information Systems Conference, pp.114-118.

Kämpfe, N., Penzhorn, J., Schikora, J., Dünzl, J., \& Schneidenbach, J. (2009). Empathy and Social Desirability: A Comparison of Delinquent and Non-Delinquent Participants using Direct and Indirect Measures. Psychology, Crime \& Law, 15(1), 1-17. http://dx.doi.org/10.1080/10683160802010640 
Karrer, K., Glaser, C., Clemens, C., \& Bruder, C. (2009). Technikaffinität erfassen-der Fragebogen TA-EG. Der Mensch als Mittelpunkt technischer Systeme, 8, 196-201.

Laib, M., \& Wolkenstein, L. (submitted). Do Body Scanners Discriminate Overweight Flight Passengers? The Effect of Body Scanners on Body Image.

Lerner, J. S., Gonzalez, R. M., Small, D. A., \& Fischhoff, B. (2003). Effects of Fear and Anger on Perceived Risks of Terrorism: A National Field Experiment. Psychological Science, 14(2), 144-150. http://dx.doi.org/10.1111/1467-9280.01433.

Maslow, A. H. (1954). Motivation and Personality. London: Harper \& Row. http://dx.doi.org/10.1111/j.14676494.1954.tb01136.x

Millisecond Software. (2012). Inquisit (Version 3.0.6.0.). Seattle, WA: Millisecond Software.

Mitchener-Nissen, T., Bowers, K., \& Chetty, K. (2012). Public Attitudes to Airport Security: The Case of Whole Body Scanners. Security Journal, 25(3), 229-243. http://dx.doi.org/10.1057/sj.2011.20

Morosan, C. (2012). Voluntary Steps toward Air Travel Security: An Examination of Travelers' Attitudes and Intentions to Use Biometric Systems. Journal of Travel Research, 51(4), 436-450. http://dx.doi.org/10.1177/0047287511418368.

Nagenborg, M. (2011). Körperscanner. In M. Maring (Ed.), Fallstudien zur Ethik in Wissenschaft, Wirtschaft, Technik und Gesellschaft (4 ed.), pp. 236-243.. Karlsruhe: KIT Scientific Publishing.

O'Donnell, A. T., Jetten, J., \& Ryan, M. K. (2010). Who is Watching over You? The Role of Shared Identity in Perceptions of Surveillance. European Journal of Social Psychology, 40(1), 135-147.

Pikkarainen, T., Pikkarainen, K., Karjaluoto, H., \& Pahnila, S. (2004). Consumer Acceptance of Online Banking: An Extension of the Technology Acceptance Model. Internet research, 14(3), 224-235. http://dx.doi.org/10.1108/10662240410542652

Pingitore, R., Spring, B., \& Garfieldt, D. (1997). Gender Differences in Body Satisfaction. Obesity Research, 5(5), 402-409. http://dx.doi.org/10.1002/j.1550-8528.1997.tb00662.x

Pohlmeyer, A. E. (2011). Identifying Attribute Importance in Early Product Development - Exemplified by Interactive Technologies and Age - Technische Universität Berlin.

Rajaonah, B., Castelli, J. C., Ravenel, J.-B., Osmont, A., Cabrol, P., \& Le Fur, G. (2014). Acceptability of Security Scanners at Airports: A French Opinion Survey. https://hal.archives-ouvertes.fr/hal-01010844/

Rubner, J. (2010). Blick durch die Kleider Sueddeutsche.de. Retrieved from http://www.sueddeutsche.de/wissen/diskussion-um-nacktscanner-blick-durch-die-kleider-1.64539

Rydell, R. J., \& McConnell, A. R. (2006). Understanding Implicit and Explicit Attitude Change: A Systems of Reasoning Analysis. Journal of Personality and Social Psychology, 91(6), 995-1008. http://dx.doi.org/10.1037/0022-3514.91.6.995

Rydell, R. J., McConnell, A. R., Mackie, D. M., \& Strain, L. M. (2006). Of Two Minds: Forming and Changing ValenceInconsistent Implicit and Explicit Attitudes. Psychological Science, 17(11), 954-958. http://dx.doi.org/10.1111/j.1467-9280.2006.01811.x

Samson, A. C., \& Huber, O. W. (2010). Short German Versions of Empathizing and Systemizing Self-Assessment Scales. Swiss Journal of Psychology, 69(4), 239-244. http://dx.doi.org/10.1024/1421-0185/a000028.

Schuler, M., \& Wolkenstein, L. (2014). Psychologie und Sicherheitstechnologie - Psychologische Auswirkungen von Sicherheitstechnologien auf den Menschen und die Einstellung von Menschen dieser Technik gegenüber. In H.-H. Gander \& G. Riescher (Eds.), Sicherheit und offene Gesellschaft - Herausforderungen, Methoden und Praxis einer gesellschaftspolitischen Sicherheitsforschung(pp. 77-109). Baden-Baden: Nomos.

Spriggs, A., Argomaniz, J., Gill, M., \& Bryan, J. (2005). Public Attitudes Towards CCTV: Results from the PreIntervention Public Attitude Survey Carried out in Areas Implementing CCTV Home Office Online Report $10 / 05$.

Strack, F., \& Deutsch, R. (2004). Reflective and Impulsive Determinants of Social Behavior. Personality and Social Psychology Review, 8(3), 220-247. http://dx.doi.org/10.1207/s15327957pspr0803_1

Traut, A., Nagenborg, M., Rampp, B., \& Ammicht Quinn, R. (2010). Körperscanner - Sicherheiten und Unsicherheiten. Forum kriminalprävention, 1, 14-20.

Wigboldus, D. H. J., Holland, R. W., \& van Knippenberg, A. (2004). Single target implicit associations. Unpublished manuscript.

Wilson, T. D., Lindsey, S., \& Schooler, T. Y. (2000). A model of dual attitudes. Psychological Review, 107(1), 101126. http://dx.doi.org/10.1037/0033-295X.107.1.101 